\title{
It's Complicated: Understanding Gender Equality in Bangkok, Thailand ${ }^{1}$ Korakit Choomgrant ${ }^{1^{*}}$ \\ ${ }^{1}$ Faculty of Tourism and Hospitality \\ Dhurakij Pundit University \\ *korakit.cho@dpu.ac.th
}

\begin{abstract}
This paper examines the state of "gender equality" in Thailand by taking the Silom precinct as an example. It is a qualitative study that analyzes analyzing information and data gathered from both primary and secondary sources. The discourse analysis method is also accommodated. What is revealed that the printed and online media have greatly influenced visitors' perceptions towards Silom as a precinct of night-life related entertainment and activity which is mostly sexually oriented, rather than as a precinct of Thailand's Wall Street. By having such interpretations, Silom is also known as commercialized gender equality for an income-generating purpose, instead of establishing greater understanding and acceptance of non-heterosexuality. In order to educate visitors about gender equality and reduce the notion of a sex-oriented business precinct, a suitable interpretation is needed and suggested by compromising all of the significant dimensions and presenting it in a provocative way to stimulate visitor's critical thinking through real-world experiences.
\end{abstract}

Keywords: Silom, Bangkok, Gender Equality, Adult Entertainment, Interpretations.

\section{Introduction}

Thailand has long been well known for its charming and outstanding cultural and natural tourism resources among international visitors for almost half a century. In addition, major cities such as Bangkok, Pattaya, Chiang Mai and Phuket are also primary tourism destinations, as well as the Thai people themselves who enhance the reputation of Thailand as a great holiday destination. Evidently a number of tourists have not been affected by the unexpected passing of late King Bhumipol from October 2016 onwards.

Current statistics show that more than 30 million tourists visited Thailand in $2016^{2}$. This could be explained as the Tourism Authority of Thailand successfully establishing public understanding through many media channels ${ }^{3}$. Moreover it is possible that many international tourists have previously booked their trips to Thailand before this sad event.

The capital city of Thailand, Bangkok, seems to be gaining greater popularity than the other cities due to its convenient transportation, well-planned city, all-in-one stop service, its nightlife entertainment, and a mixture of cultural diversity.

Emphasizing particularly the characteristics of Bangkok, the capital city has been widely perceived as one of the exotic destinations of the East by westerners due to its richness of natural and cultural tourism resources and attractions. In addition, the notion of external cultural influences mixing with the inhabitants' way of life contributes to its charm as an exciting place for visitors of all ages, races and genders. Nonetheless, Bangkok is also notorious for night life entertainment, which refers to some areas such as Soi Cowboy, Kao Sarn Road, Soi Nana, and Silom, which are continuously referred to in

\footnotetext{
${ }^{1}$ The author wishes to acknowledge the helpful comments and suggestions of Michael McAleer.

${ }^{2}$ http://www.tatnews.org/thailand-tourism-breaks-records-welcomes-30-millionth-visitor-kingdom/ retrieved on December 15, 2016.

${ }^{3}$ http://www.tatnews.org/updated-visitor-information-during-the-mourning-period-for-his-majesty-king-bhumibol-adul yadej-2/ retrieved on December 15, 2016.
} 
many published and online sites. Interestingly, in terms of gender equality, Silom seems to be the precinct that should be examined closely.

It is worth scrutinizing and examining the influence of the printed media in establishing such the reputation of Silom. Moreover, data collected from tourists in the area are also analyzed to support the characteristic of Silom and help understand gender equality in Bangkok, which could be regarded as a significant characteristic that tourists find appealing in "Sense of Place: An Interpretative Planning Handbook" (Carter, 2001) found that it is difficult and useless to interpret all of significant dimensions of the place, rather only the significance which might be of interest to visitors should be emphasized (Carter, 2001: p. 21).

Moreover, it will suggest the interpretative messages which would help to gradually erase the notorious notion of a place where sex tourism is perceived as the dominant main business in Bangkok, and also increase greater understanding of gender equality for both domestic and international visitors.

The paper is structured into four main parts. The first part presents the significance of Silom, followed by the existing interpretations and impact. The third part will examine the target audience, and the final part will suggest an alternative interpretation

\section{Thailand's Wall Street versus Nightlife Entertaining Precinct}

What most visitors see from Saladeang skytrain station is not what it was like one hundred years ago. Nowadays, it is an area where locals live, and people commute from their residences to work. Both domestic and international visitors wander and shop in the department stores, as well as relax in one of spa and massage shops, or clubs and bars, at night. It is also where various types of hotels are located because it is very convenient for visitors to travel from within this area to another place by either the skytrain or underground trains. In addition, embassies of different nations are purposefully located in this area. Not only does this precinct serve local people's daily lives, but international visitors also use the precinct in different ways.

What visitors do not see in the present day is generally presented by four phases of the precinct development, as follows:

1. In the reign of King Rama IV, when western merchants and diplomats requested the king to construct roads for horse riding activities-relaxation.

2. In the reign of King Rama V to World War 2, three more roads were constructed along with Silom Road, namely Surawongse, Sathorn and Si Phraya. People started building houses, business centers and companies. Landowners constructed more small streets in order to increase the price of their land.

3. After World War 2 to 1982, buildings with 10 or more storeys were constructed, such as the then head office of Kasikornthai Bank, Dusit Thani Hotel, Narai Hotel, and so on. During the Vietnam War, Patpong had become notorious for night life, bars and clubs, which added to the character of the Silom area.

4. After 1982 to the present, Silom has been rapidly changing. Buildings with 20-30 storeys were built such as, Silom Center Building, Taniya Building, CP Tower, Silom Complex, Kamol Sukoson Building, and many more. Moreover, in 1984, Silom Road was chosen to be an example of infrastructure change by not using electricity poles, instead placing all electricity wires underground. It made Silom Road clean and tidy.

Therefore, the metaphor of "Thailand's Wall Street" has been given to illustrate the significance of Silom as a financial institutional development, while nightlife entertainment represents the significance 
of the social interaction and the integration of people from different places and genders, the so-called a socio-cultural dimension, since it was first constructed through today.

Although both significant characteristics are evidently identified, it seems that most current visitors know Silom by its second reputation, as a place where night life activities are accessible. Following Carter's comment (2001), interpretations should be given in accordance with visitors' interests, the interpretations found on both printed and online media related to the socio-cultural dimension is therefore examined below.

\section{Existing Interpretations and Impacts}

The major purpose of this part is to understand and analyze how the Silom precinct is perceived as a gender equalized precinct, as well as a sexually-discriminated zone, by scrutinizing existing documents. This part attempts to gather various interpretations with regard to the socio-cultural dimension of Silom from two main sources, including the written guidebooks and websites. The excerpts are selected from written guidebooks from both international and Thai publishers, including Lonely Planet Bangkok and Insight Guide Bangkok, and Bangkok Bangkok by Tourism Division, Culture Sports and Tourism Department, Thailand respectively.

The three following excerpts about Silom are derived from Lonely Planet Bangkok:

"In the heart of the business zone is Bangkok's most infamous attraction, the strip clubs of Patpong. Mainly the stuff of pulp fictions, Patpong donates loads of war stories to the foreigners who partake in its naughty nightlife. It is no accident that this skin party occurs so close to the buttoned-down world of international business" (Lonely Planet, 2004: p. 92).

"It is no secret that Bangkok makes male fantasies come true. From the hostess bars where pretty young things play flirty drinking games, to the clubs with live skin shows and massage parlours with "happy endings" [...] Looming large in the visitors' imagination is the notorious Patpong district of ping-pong and 'fuckey shows'. Along two narrow soi (Soi Patpong 1 and Soi Patpong 2, off Silom), blaring neon bars with poetic names such as King's Castle, Supergirls and Pussy Galore cater mainly to a gawking public (both male and female) with circuslike sexual exploits.” (Lonely Plane, 2004: p. 135)

and

"While stepping off the Western Shelf is a gamble for many gays, Thailand's signature tolerance extends to homosexuality as well. Drawing from a diverse international and indigenous community, Bangkok's male-gay nightlife is out and open with go-go bars, late-night discos and kathoey (transvestite and transsexual) cabarets. Night spots for Thai lesbians (tom-dee), on the other hand, aren't as prominent (or segregated) and received more police scrutiny. Popular with gays and straights, Silom Soi 2 and Soi 4 have the city's highest concentration of gay clubs (Lonely Planet, 2004: p. 135)

The following interpretation is excerpted from Inside Guide Bangkok:

"[...] one of the most exciting streets, Silom Road [...] about half-way along the night market, the stalls curve off to the left along to the noisy neon-lit street of Patpong. Patpong, which is actually two exciting and sinful enough to intrigue most visitors at least once" (Inside Guides Bangkok, 2004: p. 195).

Interestingly, readers can find more information about nightlife in a separate section, which gives a brief introduction of nightlife and related problems. However it is still emphasizing the characteristics of entertainment in various forms, such as go-go bars, gay clubs, night market, restaurants and counterfeit merchandises (Inside Guides Bangkok, 2004: p. 287). The international versions of the 
previous interpretations have, more or less, established an image of Silom as a precinct where all possible sexual pleasure can be found. It refers to gender equality, on the one hand, and also represents commercialized gender equality, on the other hand.

It might be reasonable to attract Pink tourists, who have higher spending power. Choomgrant (2014) suggested that it is superficial and does not represent the acceptance of a majority population in Thailand towards gender equality. It's complicated.

An interpretation by the Thai government is presented below. Note that the Thai government's version could not avoid inserting the nightlife scene, but it is written precisely and shortly:

"One of Bangkok's major business areas linked with several streets lined with food stalls and leading restaurants. Seafood stalls sprout along the roadside near Saladeang Intersection after sunset until into the night" (Bangkok Bangkok, 2007: p. 260).

"Probably the most popular night-life spot in the city, located between Thanon Silom and Thanon Surawongse, the Patpong area is full of a-go-go bars and beer bars" (Bangkok Bangkok,2007: p. 232).

Similar to the aforementioned messages, the nightlife theme can also be found online. Two sources, Wikipedia and Bangkok.com are, respectively, presented below:

"Silom is undoubtedly one of the city's most important financial districts with many bank headquarters, financial institutions and office buildings. Fine hotels, smaller type malls and great restaurants abound in the area too - and then of course there's the famous nightlife scene of Patpong (www.bangkok.com/silom/ accessed on 15 September 2016)."

and

"Si Lom (or Silom, Thai สีลม windmill) is a sub-District and road in Bang Rak district, Bangkok, Thailand Constructed in 1851 as part of a dyke and irrigation system, Silom road has become one of Bangkok's most cosmopolitan streets and major financial center; it is the home to some of the largest companies in Thailand ex. The Charoen Phokphand Group (CP), Bangkok Bank PLC, as well as a number of insurance and securities firms, it is often dubbed the "Wall Street of Thailand". Silom offers quite a broad range of nighttime activities ranging from street side shopping to strip dancing show; both Patpong and Thanon Thaniya (Little Tokyo) having entrances from Si Lom Road.

Furthermore, it has a popular gay area. Soi 2 has several gay lounges and club, DJ Station. This very small side street, packed between the buildings, has a passport check. As well, soi 4 is popular among gays for its terraces" (http://en.wikipedia.org/wiki/Si_Lom accessed on 15 September 2016).

The online interpretations also construct the image as similar to the printed messages. If the aim of interpretation is to provoke visitors' thoughts (Tiden, 1977: p. 9), according to the interpretations above, it is highly possible that first-time visitors will only perceive Silom as a place of entertainment, free-of-monitored sexual scenario, and the disclosed scene of sex tourism and commercialized gender equality.

\section{Strengths, Weaknesses, Problems and Reflections of Such Interpretations}

The theme of interpretation is relevant to relaxation in several forms, with a highlight being sexually-related entertainment. A precinct for "social (physical) interaction" is what can be inferred from the interpretations. 
The sole and only strength of the aforementioned interpretations is straightforwardly telling reality. To tell something directly is good as visitors will have awareness in case they do not participate in any nightlife activities, and it is good for visitors who seek such entertainment. Additionally, this reflects the target group and market.

There is only one major weakness in these interpretations. The socio-cultural dimension is unsuitably and inappropriately interpreted. While the LGBTI community in Bangkok is perceived as remarkable due to its various activities helping to promote gender equality, such as The Rainbow Sky Association and The Anjaree Foundation, the interpretations as analyzed above are too commercial and do not advocate the gender equality profoundly. There are supportive reasons as follows:

First, there is substantial information regarding the socio-cultural dimension, which can be presented selectively. The 'good for revenue generating' information is chosen in accordance with the visitors' purpose of relaxation, and the marketing advertisements (Ballantyne, 1998, Carter, 2001, Choomgrant, 2009). Bangkok has long been known for prostitution and sex tourism, as well as a gay paradise. These dominantly notorious characteristics are commercialized to attract visitors who desire sexual relaxation or pleasure, as well as to express their sexuality (Choomgrant, 2009). Hence, the information and recommendation of bars and clubs' names, predominant activities, or even Thai's girls' images are being communicated and tarnished with visitors.

Although these facts exist in the society, it could be interpreted alternatively in order to help promote a sound atmosphere and setting of Silom. Moreover, it can advocate the reduction of sex-oriented visitors and workers, as well as increase an in-depth understanding of gender equality through social interaction in the Silom precinct.

Second, these interpretations create a certain mind-set, and leave no room for critical thinking or to provoke visitors' thoughts. In other words, it does not educate or enhance the visitors' experience. Moreover, the interpretations have been done by a group of people without gathering cooperation from relevant persons, stakeholders or the community (Carter, 2001: p. 10). The existing interpretations have been written in terms of their own perceptions and experiences, and do not follow the stages of making an effective interpretation. Therefore, it leads to the inappropriate and unsuitable interpretations. Though the theme of interpretation is on the right path, the process is neglected. Then it decreases the reputation of Bangkok which in Thai means Krung Thep, or City of Angels.

Problems of such interpretations directly affect the image of Bangkok and its inhabitants. While the Tourism Authority of Thailand has put much effort in presenting and promoting traditional Thai cultures, such as the recent campaign of "Discover Thainess in 2015", Silom has been given something differently. Evidently, the notion of Silom has been long constructed through historical facts and development. Silom has been perceived in such a negative interpretation. The Silom precinct has added up the unpleasant image of Bangkok, and Thai women have been perceived negatively. This problem will be even more obvious when visitors experience the site.

The pre-knowledge either from guidebooks or websites is stored in visitors' memories. Staiff (2003) mentions that meaning making will be fully done once visitors experience the actual site and within the tourism context. It reaffirms the notorious notion of Bangkok, but it is also positive for the 'gender equality' perspective. Non-heterosexuality has been commercialized and this has an impact on visitors' perceptions of true 'gender equality' in Bangkok.

Examples of thoughts and opinions of experienced visitors at Silom strongly support the above analysis. 15 international and domestic visitors replied in interviews when asked about what they first thought of when talking about Silom. Gay bars, clubs, girls, spa and massage parlours are how $90 \%$ of visitors replied. Only $10 \%$ mentioned the restaurants and food stalls. It might be assumed that the 
understanding of the Silom precinct in relation to the socio-cultural dimension is remarkably limited. In short, the existing interpretations fail to comply with the objectives of effective interpretation, which should present a "socio-cultural dimension" to enhance and advocate gender equality rather than the exploitation of commercialized sexual activities.

\section{Target Audience/Market}

The characteristics of visitors at the sites have been personally observed many times. There are an almost equal number of local and foreign visitors. They seem to be between 20-50 years of age. Groups of friends, a couple or a single visitor are seen along Silom Street. They look very excited to discover commodities sold on the pedestrian walkway and in soi (small streets). The author has to admit that he did not enter clubs or bars in the Patpong district but observed that many foreigners were drinking and watching skimpy go-go girls. Having participated in Silom Soi 2, where a mixed group of all genders could be noticed, but dominated by homosexuals, the author observed that they were networking with each other. It can be concluded that the characteristics of visitors in the Silom precinct are highly variable in terms of demography and sexual orientation.

The educational level and real motivation have not been scrutinized in detail, but research on Singaporean homosexual men in Bangkok (Choomgrant 2009, 2014) on indicates that they hold at least a bachelor's degree, and visit Thailand because they want to release stressfulness from being unable to express their sexuality. However, it cannot be generalized that all visitors should have similar demographic characteristics. Nonetheless, it can be assumed that visitors from very strict heterosexual cultural nations who visit the Silom precinct may probably have similar patterns as those from Singapore.

From interviews, westerners from Europe, America and Australia are familiar with the sexually indiscriminate environment, but the notion of a sexually commercialized zone has already been embedded into their perceptions by a variety of printed and online media, as mentioned above. They visit the Silom precinct because they are looking for friendship and social interactions, as well as relaxation in an inexpensive area. In addition, the notion of "gender equality" is stated.

\section{An Alternative Interpretation}

There is no official interpretation made at the site, such as brochures, leaflets, or interpretative signs. Instead there are numerous off-site interpretations, including guidebooks and websites, as analyzed in previous sections. Those interpretations, in relation to the socio-cultural dimension, focus only on nightlife related activities and are presented in an unpleasant and unflattering way. It detracts from the notion of a country with beautiful traditions and cultures, as shown in the media with regard to the negative thoughts of foreign visitors during the period of mourning for the passing of King Bhumibol that purportedly ruined their holidays and nightlife ${ }^{4}$.

To propose an alternative interpretation for Silom is not an easy task, but it is possible. The following interpretation is an attempt to balance the "discourse" of Thailand reputation made by the Tourism Authority of Thailand, and the notion of Silom that is perceived by many visitors. The prime aim of this alternative interpretation, apart from "balancing", is to communicate with visitors that Silom is where sexual equality is observed, and to provoke visitors to think about this issue and further problems related to the entertainment activities in Silom.

The alternative interpretation below is suggested to compromise various characteristics and notions and apart from entertaining visitors, is to educate domestic and international visitors regarding the

\footnotetext{
${ }^{4}$ http://www.worldofbuzz.com/tourists-complained-death-thai-king-ruined-holiday/ retrieved on October 19, 2016
} 
gender equality issue, promotion of non-sexual discrimination activities, and enhance a greater understanding of the socio-cultural significance of the precinct. It is also to emphasize the feature of a shared space, where all people, regardless of their sex, gender, religion, nationality, or physicality, could associate without discrimination, and also serve the purpose of the "Tourism for All" campaign.

The interpretation is proposed as follows;

"Standing on the Saladeang sky train station, the edge of the light blue sky could be beautifully seen on the top of many well-decorated skyscrapers. Looking down on the clean and long Silom road, many green trees stand along and almost block the bottom of those tall buildings. Office workers are walking steadily through trees to get into and out of high edifices. The busy life could be observed for all day and night. Once the sun sets, people of all races and genders come with well-cut and trendy outfits to engage in what they prefer, one of many selections of entertainment. They are mixed on both sides of the pedestrian walkway. Here lively and friendly local and visitors interact while visitors negotiate the price of some goods at one of a hundred stalls. Some of them arrive late to relax at one of the night clubs or bars. The only requirement to be admitted to the bars and clubs is over 20 years old and present a document showing you are old enough to drink, dance and watch the sexy show! Regardless of gender and race, you can join every club and bar, whether it is intended for gays or straights. There is no law prohibiting you from doing that. Entertainment is for everyone. Have you ever thought of Silom one hundred years ago? It was also a relaxing and entertaining precinct where locals met foreigners. This is a way Silom creates friendship and relationship by Thai hospitality and culture. Believe it or not, you judge it."

Maybe it's not so complicated.

\section{References}

Ballantyne, B., Paker, J. \& Beckham, E., 1998. Targeted Interpretation: Exploring Relationships among Visitors' Motivations, Activities, Attitudes, Information Needs and Preferences. Journal of Tourism Studies, 9(2): 14-25.

Bangkok Metropolitan Administration, 2007. Bangkok Bangkok, Bangkok: Comform Publishers.

Choomgrant, K., 2009. Expression of Sexuality and Lifestyles in Bangkok and Singapore: A Case of Singaporean Homosexual Men. Unpublished Master of Arts Thesis, Lund University, Sweden.

Choomgrant, K., 2014. 'Out of the Closet: An Understanding of 'Queer Heritage' in the Context of Southeast Asia”. Unpublished Doctoral Dissertation, Silpakorn University, Thailand.

Griffiths, C (ed), 2004. Insight Guide Bangkok. Singapore: Insight Print Services.

http://en.wikipedia.org/wiki/Si_Lom, retrieved on 15 September 2016.

http://www.tatnews.org/thailand-tourism-breaks-records-welcomes-30-millionth-visitor-kingdom/ retrieved on December 15, 2016

http://www.tatnews.org/updated-visitor-information-during-the-mourning-period-for-his-majesty-kin g-bhumibol-adulyadej-2/ retrieved on December 15, 2016.

http://www.worldofbuzz.com/tourists-complained-death-thai-king-ruined-holiday/ retrieved on October 19, 2016

Lonely Planet Bangkok, 2004. London: Lonely Planet .

Staiff, R., \& Bushell, R. 2003. Travel Knowledgeably: The Questions of Content in Heritage Interpretation. In R. Black and B.Weiler (eds.), Interpreting the Land Down Under: Australian Heritage Interpretation and Tour Guiding, Golden, Colorado: Fulcrum Publishing.

Tilden, F., 1977. Interpreting Our Heritage, $3^{\text {rd }}$ ed., Chapel Hill: University of North Carolina Press. www.bangkok.com/silom/ retrieved on 15 September 2016. 